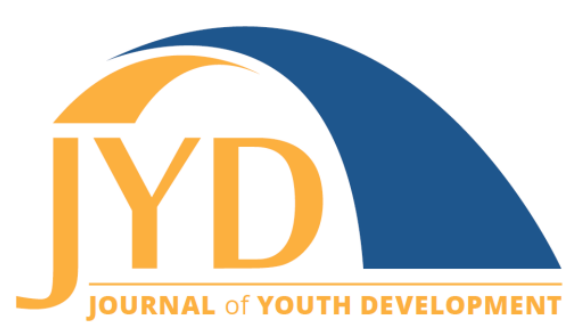

http://jyd. pitt. edu/ | Vol. 14 Issue 2 DOI 10.5195/jyd.2019.703 | ISSN 2325-4017 (online)

\title{
Teens in the Somali Diaspora: An Evaluative Program Study
}

\section{Jennifer A. Skuza}

University of Minnesota, Extension Center for Youth Development

skuza@umn.edu

\begin{abstract}
Program evaluation is a critical part of program sustainability because evaluation can inform improvements and document impact. Here, 2 Minnesota organizations came together in partnership with the Somali American community to work toward a shared vision, which was to develop a new sustainable program that prepared refugee and immigrant youth for their educational and workforce futures while supporting their cultural way of being. This article shares the evaluative study of this program, which reached teens in the Somali diaspora living in Minnesota. The program team had a long-term interest in developing an evidence-based model to suit this special population; this evaluation study was viewed as a step toward becoming evidence-based. The Somali American community supported the study because they valued the program and saw its cultural relevance. The evaluation used pre- and post-program surveys to capture program impacts in 2 outcome areas: workforce preparation and higher education preparation. Results showed that youth participants made gains in their perceptions of both outcome areas. However, gains displayed were unrelated to program attendance. Limitations and recommendations for future evaluation plans are provided.
\end{abstract}

Key words: youth development, refugee, immigrant, evaluation, sustainability

\section{Introduction}

Program evaluation is a critical part of program sustainability because evaluation can inform improvements and document impact. But it can take several attempts to get a program evaluation design correct. This was especially the case for the program featured in this article. Here, two Minnesota organizations came together in partnership with the Somali American community to work toward a shared vision, which was to develop a new sustainable program that prepared refugee and immigrant youth for their educational and workforce futures while

(c) $\mathbf{E Y}$ New articles in this journal are licensed under a Creative Commons Attribution 4.0 License. This journal is published by the University Library System, University of Pittsburgh and is cosponsored by the University of Pittsburgh Press. The Journal of Youth Development is the official peer-reviewed publication of the National Association of Extension 4-H Agents and the National AfterSchool Association. 
Teens in the Somali Diaspora

supporting their cultural way of being. This article focuses on the evaluative study of that program, which reached teens in the Somali diaspora living in Minnesota. This kind of programming is important because it serves a special population with unique life circumstances; therefore, it is critical to have a culturally responsive evaluation design that can support the program's sustainability. The ultimate purpose of the evaluation was to test an evaluation strategy and to learn how best to execute it with this youth audience. The team used a preand post-program survey with youth participants to capture program impacts in two outcome areas: workforce preparation and higher education preparation. Next, I will turn to a definition of terms related to the youth in this study.

\section{Refugees and Immigrants}

All the youth in this study were either refugees or children of refugees. Refugees are people forced to leave their country without the option to return (The UN Refugee Agency USA, 2018). Refugees are either unable or unwilling to return to their home country for a variety of reasons, but often for fear of persecution due to their race, religion, nationality, political beliefs, or membership in a social group. An immigrant is someone who decides to leave and seek residence in a new country (Cameron, 2010). The fundamental difference between refugees and immigrants is the element of choice. Immigration is considered a natural phenomenon in population ecology, whereas refugee movement occurs under coercion or pressure.

\section{Background on Somali Americans in Minnesota}

Today, Minnesota is home to one of the world's largest Somali diaspora populations (Yusuf, 2012). The Minnesota State Demographic Center (2018) reports that nearly 74,000 people in Minnesota speak Somali. Ethnic Somalis first immigrated to Minnesota in the 1980s and earlier, many to attend universities or establish businesses. However, the Somali refugee story tracks to 1991, when civil war broke out in Somalia. Millions fled to refugee camps, many in Kenya and Ethiopia. From there, some Somalis immigrated to the United States and other collaborating countries. A wave of Somalis began arriving in Minnesota in 1992. Some came as refugees, while others arrived as immigrants through the sponsorship of family members, or relocated to Minnesota from elsewhere in the United States (Minnesota Historical Society, 2010). There were many more refugees than visas available, so it was common for one family member to arrive alone. Once a refugee or immigrant was established in the United States, that person could petition the government for visas for family members. Many Somalis chose Minnesota because 
Teens in the Somali Diaspora

of their social networks; others chose Minnesota for educational and employment opportunities and to access an array of services (Wilhide, 2018). Minnesota is a conducive resettlement location because of its infrastructure of nonprofit agencies and nongovernmental organizations focused on resettling refugees (Almond \& Nazaryan, 2016).

\section{A Focus on Somali American Youth in Minnesota}

Somali parents and community leaders in Minnesota worry that the youth are forgetting their culture, language, and religion (Wilhide, 2018). Despite this perception, research shows that the youth are holding fast to a national and ethnic identity (Bigelow, 2009). They are quickly becoming citizens of their new countries while still strongly identifying themselves as Somali and Muslim (Berns McGown, 1999; Shah, 2006). As Mohamed Jama, a Somali youth leader, put it, "Most of our young people are not losing culture, but they are entwining with the culture" (as cited in Wilhide, 2018, "Balancing Cultures," para. 2).

This fear of cultural loss also explains why Somali American youth, for the most part, have low participation rates in youth programs. Parents often think such programs are too disconnected from their Somali identity (TAYO Consulting Group, 2016; Tzenis, 2018). Yet research shows that youth programs are among the few places where refugee and immigrant youth have a chance to truly get to know themselves and their peers (Skuza, 2005). Participation in youth programs is also associated with positive social outcomes such as academic success, social relationships and behaviors, reduced problem behavior, and identity development (Mahoney, Larson, Eccles, \& Lord, 2005).

Recognizing the need to engage Somali American youth in programs, Ka Joog, a Somali American youth-serving organization in Minneapolis, Minnesota, partnered with Minnesota 4-H Youth Development. Together these two organizations produced a program model and an evaluation strategy, engaging the Somali American community in the Minneapolis and St. Paul area to build it.

\section{Program Model Description}

A STEAM club was the main component of the program model. The clubs were designed to ignite adolescents' interests in science, technology, engineering, arts, and mathematics (STEAM) while preparing them for higher education and career pathways. Club participants 
Teens in the Somali Diaspora

were Somali American teens experiencing educational barriers and living in the Minneapolis and St. Paul area. The program year ran from September to August, and the project operated for five years from 2013 to 2018. During the school year, three clubs met twice a week for 4 contact hours over 33 weeks and were facilitated by two multilingual adults who worked in partnership with youth participants and their families. In addition to receiving homework help, youth applied their learning to scientific inquiry and practical engineering problems. Club activities equipped them with leadership skills needed to pursue higher education and careers. They also participated in arts to explore and express their cultural background. Each summer youth participated in a University of Minnesota campus immersion experience, where they learned about student life, explored academic interests, and identified steps toward college readiness. The goal of this program was to develop a sustainable program model that prepared Somali American youth for their educational and workforce futures while supporting their cultural way of being.

It is important to note that the program model in this project started as a STEM club. However, early community input recommended the addition of arts, which transformed the program model into a STEAM club. Performing arts, cultural arts, spoken word and music were then used as a means of engagement, to encourage and empower youth, and as a way to preserve Somali culture. The arts complemented the content learning in science, technology, engineering, and mathematics.

This program model change was reflective of how the program team approached the implementation of this project. The team was responsive and continuously adjusted the implementation methods to better suit the target audience. It is also important to note that the audience was migratory. Throughout a given year, a number of youth and family members would travel back and forth from Minnesota to Somalia or Kenya to visit and care for family members they were separated from. The program team was committed to maintaining a continuous feedback loop with the Somali American youth program participants and their extended families ensuring the program met their needs.

\section{Evaluation Methodology}

With the support of the Somali American community, the program team viewed this evaluation study as a step toward becoming evidence-based. As previously indicated, the ultimate purpose was to test an evaluation strategy and learn how best to execute it with this Somali American youth audience. The evaluation approach included a pre- and post-program survey of youth 
Teens in the Somali Diaspora

participants. The program team had tested a variety of evaluation instruments throughout the course of the project before landing on this survey method. In the final year of the project, the team used this method to capture program impacts in two outcome areas: workforce preparation and higher education preparation.

Twenty-five youth (30\% female and $70 \%$ male) completed both the pre- and post-program surveys, using the same 82-item paper-and-pencil survey instrument. These youth participated in the clubs for either 1 or 2 years. The pre survey was administered in October 2017 and the post survey was administered in May 2018. The surveys were delivered during club sessions, and program leaders walked youth through survey questions in English and Somali. The team also tracked program participant attendance.

\section{Survey Data Analysis}

As indicated in the project's evaluation report (Fields, Dupuis, Halloran, \& Chamberlain, 2018), the team first determined the survey items to be used for the intended outcomes (youth perception of their workforce preparation and youth perception of their higher education preparation). As shown in Table 1, the workforce preparation outcomes consisted of 6 items; the higher education preparation outcome consisted of 11 items. Next, the following variables were constructed separately for the pre and post surveys for each youth: the average response score of the items corresponding to each outcomes, and the change score (i.e., post survey score compared to pre survey score).

The second step was to construct a variable that could be used to examine the effect of program attendance. To do so, a dosage variable was computed based on the youth participants' attendance rates. Because each program site held a different number of sessions, site-specific attendance rates did not provide a comparable measure program-wide. Therefore, to standardize attendance rates across the sites, the number of days a youth attended the club was divided by the total number of possible sessions offered across all sites (which was 66). The resulting value was then multiplied by 100 to get an attendance rate that corresponds to the percentage of days a youth attended a club.

Next, it was determined which participants were eligible to be in the study. To be included, a youth needed to have completed both the pre- and post-program surveys and have attendance data available. A total of 25 youth from the three club sites met the inclusion criteria. 
Teens in the Somali Diaspora

Table 1. Survey Items Used in this Study

\begin{tabular}{|c|c|}
\hline $\begin{array}{l}\text { Program } \\
\text { outcome } \\
\text { area }\end{array}$ & Survey item \\
\hline $\begin{array}{l}\text { Workforce } \\
\text { preparation }\end{array}$ & $\begin{array}{l}\text { I get in touch with experts and get as much information as I can before making } \\
\text { decisions about my education. } \\
\text { There is no one I can watch to find out about the kind of work I might like to do. } \\
\text { When it is time to make an important job or education decision, I am able to make an } \\
\text { appropriate plan. } \\
\text { I do not know which skills are most important to learn that will help me in the future. } \\
\text { It is important to know science to get a good job. } \\
\text { Having a job that involves science, math, engineering, and technology would help me } \\
\text { be successful in life. }\end{array}$ \\
\hline $\begin{array}{l}\text { Higher } \\
\text { education } \\
\text { preparation }\end{array}$ & $\begin{array}{l}\text { When solving a problem, I am able to think everything through in my own head. } \\
\text { When it comes to solving a problem, I think about all of the things that are part of the } \\
\text { problem before deciding what to do. } \\
\text { I can tell the differences between talk that is backed up by facts and talk that is not } \\
\text { backed up by anything. } \\
\text { I use information I get to help me think about several different ways to solve a } \\
\text { problem. } \\
\text { I can solve problems through the use of logic. } \\
\text { Science, technology, math, and engineering are good for the future of our country. } \\
\text { I am good at science. } \\
\text { I am good at using technology. } \\
\text { When something new is discovered, I like to learn about it quickly. } \\
\text { I am interested in taking more classes that involve engineering. } \\
\text { I am interested in taking more classes that involve science. }\end{array}$ \\
\hline
\end{tabular}

Note. Response scale options for all items were: completely disagree, mostly disagree, mostly agree, and completely agree. Source: Fields, et al. (2018). 2017-2018 CYFAR Evaluation Report. Center for Applied Research and Educational Improvement, College of Education and Human Development, University of Minnesota.

To complete the statistical analysis, the evaluation team first computed descriptive statistics and generated histograms separately for all variables in the study. This allowed the evaluators to explore patterns in the data and identify any coding errors (which were subsequently 
Teens in the Somali Diaspora

corrected). Second, the team explored the bivariate relationships between each combination of study variables using Pearson product moment correlations.

Finally, the evaluation team tested the statistical significance of the relationship between program attendance (i.e., program dosage) and each program outcome (workforce and higher education preparation) separately via single-level regression. A regression model was fitted to each outcome separately, where the post survey variable served as the outcome variable, the pre survey variable served as a control variable, and the attendance rate variable was the primary predictor of interest. An interaction term between attendance rate and the pre-program survey control variable was also included to test whether any effect of attendance was the same regardless of a youth's pre survey score.

\section{Survey Results}

The first step of the analysis was to create the seven variables of interest: pre survey and post survey response score means for workforce preparation and higher education preparation outcomes, change scores to indicate the difference in the pre and post survey mean for workforce preparation and higher education preparation outcomes, and an attendance rate variable. The study team explored each of these variables descriptively (see Table 2).

Youth responding to the survey items related to these two outcomes were given four possible response options: completely disagree, disagree, agree, and completely agree. A response of completely disagree corresponds with a score of 1 , and a response of completely agree corresponds with a score of 4 . A higher mean score corresponds to higher levels of agreement.

\section{Program Outcomes}

Regarding the workforce preparation outcome, the results showed an increase of 0.08 in the mean score of these items from the pre-survey (3.13) compared to the post-survey (3.21). For the higher education preparation outcome, the results also showed an increase in the average score (this changed from a mean of 3.34 on the pre survey to a mean of 3.44 on the post survey, a change of 0.10 ). Not only did youth participants' scores in both domains increase from pre- to post-program survey, but the variability in their scores decreased from pre survey to post survey, suggesting less variability in how students respond to the survey after program participation than at the beginning of program participation. Finally, the negative minimum values for the change variables showed that not all youth participants' level of agreement 
Teens in the Somali Diaspora

increased from pre survey to post survey; in fact, some showed a decrease. Overall, 16 of the 25 youth (64\%) showed increases in their level of agreement from pre- to post-program survey on their individual scores for the workforce preparation outcome, while 15 of 25 students (60\%) showed increases from pre- to post-program survey for the higher education preparation outcome.

\section{Attendance}

The average attendance rate for the youth who met the criteria was $46 \%$, with a minimum attendance rate of $2 \%$ and a maximum attendance rate of $68 \%$. An attendance rate of $46 \%$ corresponds to approximately 30 days of programming (i.e., the mean), while the median number of days attended was slightly higher, at 32 days. The sample of youth participants attended from one to 45 program days.

The next step was to compute the Pearson product moment correlations between each combination of study variables to explore the bivariate relationships between the variables in the study in order to understand how program participation was related to program outcomes. The correlations are shown in Table 3. The workforce preparation and higher education preparation variables showed strong positive correlations, both at pre-program survey $(0.89)$ and at post-program survey (0.68). Similarly, the higher education preparation variable representing change from pre- to post-program was highly correlated with the workforce preparation variable representing change from pre survey to post survey $(0.67$, not shown in Table 3). These results suggest that youth participants' perceptions of their preparations for the workforce and their preparation for higher education are highly related to each other.

Of particular interest were the correlations between the workforce preparation and higher education preparation variables and the attendance rate (i.e., program dosage). The results showed that the attendance rate was moderately correlated with both workforce preparation (0.28) and higher education preparation (0.33) at pre-program survey time, which means that participants who had better attendance throughout the year started with a higher score on these two outcome variables. In contrast, the results showed no relationship between attendance rate and the workforce preparation $(-0.05)$ and higher education preparation $(0.04)$ at post-program survey time, which means that youth participants' scores at the end of the program were unrelated to their attendance rate. The final step for study analysis was to fit a regression model to the workforce preparation variable at post survey and the higher education preparation variable at post survey separately in order to test the statistical significance of the 
relationships. The pre-program survey variables were included as control variables, and the attendance rate was the predictor of primary interest. An interaction term between the pre survey variable and attendance rate was also included. The results showed that, for both domains, none of the variables were statistically significant (all $p>.05$ ). This result suggested that the gains youth displayed were unrelated to program dosage.

The results also showed that, on average, the youth participants' levels of agreement increased from pre-program to post-program for both the workforce preparation domain and the higher education preparation domain. Regarding individual youth, for both domains, over half of the youth showed an increase in level of agreement from pre-program to post-program. Further, the results showed a strong relationship between youth participants' perceptions of their preparation for workforce and their perceptions of their preparation for higher education.

On average, youth attended over 30 of the 66 program days (or $46 \%$ of programming). The results showed that program dosage was unrelated to program outcomes, suggesting the gains displayed were unrelated to program attendance.

Table 2. Descriptive Statistics of Survey Responses

\begin{tabular}{|c|c|c|c|c|}
\hline Variable & Mean & SD & Minimum & Maximum \\
\hline \multicolumn{5}{|l|}{ Workforce preparation } \\
\hline 1. Pre-program survey & 3.13 & 0.66 & 2.00 & 4.00 \\
\hline 2. Post-program survey & 3.21 & 0.48 & 2.33 & 4.00 \\
\hline 3. Change & 0.08 & 0.79 & -1.50 & 2.00 \\
\hline \multicolumn{5}{|c|}{ Higher education preparation } \\
\hline 4. Pre-program survey & 3.34 & 0.06 & 2.00 & 4.00 \\
\hline 5. Post-program survey & 3.44 & 0.54 & 1.91 & 4.00 \\
\hline 6. Change & 0.10 & 0.64 & -0.73 & 1.55 \\
\hline 7. Attendance rate & $46 \%$ & $16 \%$ & $2 \%$ & $68 \%$ \\
\hline
\end{tabular}

Note. SD = standard deviation. Source: Fields et al. (2018). 2017-2018 CYFAR Evaluation Report. Center for Applied Research and Educational Improvement, College of Education and Human Development, University of Minnesota. 
Teens in the Somali Diaspora

Table 3. Correlations Between Study Variables

\begin{tabular}{|c|c|c|c|c|c|}
\hline \multirow[b]{2}{*}{ Variable } & \multicolumn{2}{|c|}{ Pre-program } & \multicolumn{2}{|c|}{ Post-program } & \multirow[b]{2}{*}{ Attendance } \\
\hline & $\begin{array}{l}\text { Workforce } \\
\text { preparation }\end{array}$ & $\begin{array}{l}\text { Higher ed } \\
\text { preparation }\end{array}$ & $\begin{array}{l}\text { Workforce } \\
\text { preparation }\end{array}$ & $\begin{array}{l}\text { Higher ed } \\
\text { preparation }\end{array}$ & \\
\hline \multicolumn{6}{|c|}{ Pre-program } \\
\hline $\begin{array}{l}\text { Workforce } \\
\text { preparation }\end{array}$ & 1.00 & & & & \\
\hline $\begin{array}{l}\text { Higher ed } \\
\text { preparation }\end{array}$ & .089 & 1.00 & & & \\
\hline \multicolumn{6}{|c|}{ Post-program } \\
\hline $\begin{array}{l}\text { Workforce } \\
\text { preparation }\end{array}$ & 0.08 & 0.11 & 1.00 & & \\
\hline $\begin{array}{l}\text { Higher ed } \\
\text { preparation }\end{array}$ & 0.44 & .037 & 0.68 & 1.00 & \\
\hline Attendance & .028 & .033 & -0.05 & 0.04 & 1.00 \\
\hline
\end{tabular}

Note. Source: Fields et al. (2018). 2017-2018 CYFAR Evaluation Report. Center for Applied Research and Educational Improvement, College of Education and Human Development, University of Minnesota.

\section{Discussion and Recommendations}

This evaluation study allowed this program to take a step toward becoming evidence-based. The program team was interested in testing an evaluation strategy and learning how to best execute it with this Somali American youth audience. This evaluation, like the entire project, was about pioneering new strategies. For instance, the partnership between Ka Joog and Minnesota 4-H Youth Development was new. The STEAM club model was new. This program was the first time many of the youth had ever participated in a program, outside of school, in the United States. The Somali American youth and their families were new to living in Minnesota. Participating in an evaluation was new to the target audience; however, the youths' families supported the study because they valued the program.

One limitation of this study was using attendance data. In a national study of 4-H programs, Arnold (2018) indicated that youth engagement is critical, as program participation alone does not lead to outcomes. She recommends that duration, intensity, and breadth of program experience may be more powerful variables to track because they point to youths' levels of 
Teens in the Somali Diaspora

engagement. Therefore, it would be beneficial, in future studies, to redesign the evaluation and collect more nuanced data, beyond attendance, such as how long youth participate in the program (duration), how much youth do during their program experience (intensity), and the number of extended learning opportunities youth participate in outside of the regular club sessions (breadth).

Another limitation of the study concerns sample size. It is possible that the non-statistically significant results in this evaluation can be attributed to the small sample and therefore a lack of statistical power. Thus, it would be beneficial in future evaluations to increase the number of youth participants who complete both the pre- and post-program surveys. As previously mentioned, a number of the program's youth and family members traveled back and forth between Minnesota and Somalia or Kenya to visit and care for family members from whom they were separated. Recognizing the migratory nature of the audience, finding a more suitable timeline for data collection (that was coordinated with the families' travel schedules) might help to increase the number of participants who are able to complete surveys both before and after the program.

\section{Summary}

Two organizations came together in partnership with the Somali American community to work toward a shared vision, which was to develop a new sustainable program model that prepared youth for their educational and workforce futures while supporting their cultural way of being. Using a STEAM club program model, the team worked with teens in the Somali diaspora using a youth development process where young people and their families were viewed as resources and partners. The program team was committed to the evaluation. Over the course of the 5year project, the team tested a variety of evaluative instruments. In the final year of the project, the team used a pre- and post-program survey with youth participants to capture program impacts in two outcome areas: workforce preparation and higher education preparation. The purpose of the evaluation was to test an evaluation strategy and learn how best to execute it with this Somali American youth audience.

The results show that, on average, youth participants made gains in their perceptions of the workforce preparation outcome and the higher education preparation outcome. Further results showed a strong relationship between their perceptions of their workforce preparation and their perceptions of their higher education preparation-as one went up, so did the other from the pre-program to the post-program survey. The results showed that program dosage was 
Teens in the Somali Diaspora

unrelated to program outcomes, suggesting gains displayed were unrelated to program attendance. Therefore, redesigning the evaluation to collect data related to duration, intensity and breadth could yield results that speak to youth engagement. Increasing the number of youth participants who complete both the pre and post surveys would potentially increase the statistical power. This could be done by securing more participants and adjusting the data collection timeline to accommodate participant schedules due to the migratory nature of the audience. The program team looks forward to improving the evaluation design in future studies and addressing other factors that could support sustainability.

\section{References}

Almond, K. \& Nazaryan, A. (2016, May). Somalis finding their place in Minnesota: A look at the day-today lives of people in Minnesota's Somali community, the largest in the United States. CNN U.S. Edition. Retrieved from http://www.cnn.com/interactive/2017/02/us/somali-minnesota-photos/

Arnold, M. (2018). From context to outcomes: A thriving model for 4-H Youth Development programs. Journal of Human Science and Extension, 32(1), 141-160. Retrieved from https://docs.wixstatic.com/ugd/c8fe6e_755e5c14ab3f4d03ac84b3250597f613.pdf

Berns McGown, R. (1999). Muslims in the diaspora: The Somali communities of London and Toronto. Toronto, Canada: University of Toronto Press.

Bigelow, M. (2009) Somali adolescents' negotiation of religious and racial bias in and out of school. Theory Into Practice, 4オ1), 27-34. doi:10.1080/00405840701764706

Cameron, L. A. (2010). The Minnesota immigrant experience. Minnesota Historical Society. Retrieved from http://collections.mnhs.org/mnhistorymagazine/articles/62/v62i03p096-106.pdf

Fields, J., Dupuis, D. Halloran, C. \& Chamberlain, R. (2018). 2017-2018 CYFAR Evaluation Report. Minneapolis: Center for Applied Research and Educational Improvement, College of Education and Human Development, University of Minnesota.

Mahoney, J. L., Larson, R. W., Eccles, J. S., \& Lord, H. (2005). Organized activities as development context for children and adolescents. In J. L. Mahoney, R. W. Larson, \& J. S. Eccles (Eds.), Organized activities as contexts of development: Extracurricular activities, after-school and community programs (pp. 3-22). Mahwah, NJ: Lawrence Erlbaum.

Minnesota Historical Society. (2010). Becoming Minnesotan: Stories of recent immigrants and refugees. Retrieved from http://education.mnhs.org/immigration/communities/somali

Minnesota State Demographic Center. (2018). Immigration \& language. Retrieved from https://mn.gov/admin/demography/data-by-topic/immigration-language/

Shah, S. (2006). Leading multiethnic schools: A new understanding of Muslim youth identity. Educational Management Administration \& Leadership, 34, 215-237. 
Skuza, J. (2005). Understanding the experiences of immigrant adolescents: Acculturation is not the same as assimilation. In P. Witt \& L. Caldwell (Eds.), Recreation and youth development (pp. 384-405). State College, PA: Venture Publishing.

TAYO Consulting Group. (2016). Pathways to dignity: A human security approach to uplift Minnesota's Somali youth. Retrieved from http://tayocg.com/resources/

Tzenis, J. (2018). Contradictions of belonging: The educational aspirations and agency of youth in the Somali diaspora (Doctoral dissertation). Retrieved from ProQuest. (10829271)

The UN Refugee Agency USA (2018). The refugee brief. Retrieved from http://www.unhcr.org/enus/refugees.html

Wilhide, A. February 27, 2018. Somali and Somali American experiences in Minnesota. MNopedia, Minnesota Historical Society. Retrieved from http://www.mnopedia.org/somali-and-somaliamerican-experiences-minnesota

Yusuf, A. I. (2012). Somalis in Minnesota. St. Paul, MN: Minnesota Historical Society. 